\title{
Utilization and Expenditure of Anti-cancer Medicines in Kosovo: Findings and Implications
}

\author{
Arianit Jakupi $^{1,2} \cdot$ Brian Godman $^{3,4,5}$ (1) Antony Martin ${ }^{5}$ Alan Haycox ${ }^{5}$ \\ Indrit Baholli ${ }^{6}$
}

Published online: 2 February 2018

(c) The Author(s) 2018. This article is an open access publication

\begin{abstract}
Background and Objective The Ministry of Health (MoH) leads and organizes health policy in Kosovo, which includes procurement and provision of medicines, including anti-cancer medicines, which compose a special group of medicines. However, there has been limited analysis of the utilization and expenditure on anti-cancer medicines in Kosovo; consequently, the objective of this study is to undertake research to provide future guidance on the use of anti-cancer medicines.
\end{abstract}

Brian Godman

brian.godman@strath.ac.uk; Brian.Godman@ki.se;

Brian.Godman@liverpool.ac.uk

Arianit Jakupi

arianit.jakupi@ubt-uni.net; arianit.jakupi@ rks-gov.net;

arianiti@gmail.com

Antony Martin

a.p.martin@liverpool.ac.uk

Alan Haycox

a.r.haycox@liverpool.ac.uk

Indrit Baholli

indrit.baholli@uet.edu.al

1 Faculty of Pharmacy, UBT Higher Education Institution, Prishtina, Kosovo

2 Pharmaceutical Consulting, Prishtina, Kosovo

3 Strathclyde Institute of Pharmacy and Biomedical Sciences, University of Strathclyde, Glasgow, UK

4 Department of Laboratory Medicine, Division of Clinical Pharmacology, Karolinska Institute, Karolinska University Hospital Huddinge, Stockholm, Sweden

5 Health Economics Centre, University of Liverpool Management School, Liverpool, UK

6 European University of Tirana, Tirana, Albania
Method National drug utilization data is available in Kosovo. Utilization and expenditure on anti-cancer medicines [Anatomical Therapeutic Chemical (ATC) code L], initially from 2011 to 2013, especially for anti-cancer medicines on the essential medicines list was analysed from national data. In addition, current systems for procuring and managing anti-cancer medicines in Kosovo was documented.

Results There was appreciable variability in the utilization of anti-cancer medicines over the years, with low or limited use of some anti-cancer medicines on the Essential Medicine List. This is a concern in view of their essential medicine status. From 2011 to $2013, € 16.49$ million was spent on anti-cancer medicines (ATC L). The process of selection of new medicines begins with suggestions from doctors at the University Clinical Centre in Kosovo.

Conclusion The analysis has shown appreciable variation with current utilization patterns for anti-cancer medicines in Kosovo. This needs to be addressed as part of improving the drug management process to optimize patient care within available resources. Future years and reforms need to be assessed to improve current utilization and expenditure patterns. 


\section{Key points for decision makers}

There are considerable discrepancies regarding the current utilization patterns of anti-cancer medicines in Kosovo as there was no utilization of some anticancer medicines considered vital, essential, or necessary based on the essential medicine list.

Only a few anti-cancer medicines have very high expenditure; however, there are variations in their use across the years.

The MoH should carefully consider introducing updated processes for the selection and pricing for new medicines.

\section{Introduction}

For many years health authorities across the world have published annual medicine consumption data, which have been widely used among key stakeholder groups. This includes monitoring the influence of ongoing reforms and initiatives, and using the outputs to plan future initiatives and budgets [1-4]. This is particularly the case in a number of European countries where health authorities and health insurance agencies strive towards universal access within finite budgets.

In Kosovo currently, the Ministry of Health (MoH) leads and organizes health policy processes, achieving many of its objectives through subordinate institutions such as the Kosovo Medicines Agency (KMA). The KMA is responsible for the public health of the population by ensuring drug safety, quality, and efficacy, as well as overseeing the importation of medicines into Kosovo and conducting analyses of overall drug consumption.

New anti-cancer medicines are typically seen as a special group of medicines as this is an emotive area, generally leading to greater leeway for pricing considerations and funding than for other medicines, such as those for cardiovascular diseases or mental health $[5,6]$. There is growing concern worldwide regarding these drugs, with prices of cancer medicines rising up to tenfold during the past 10 years in some countries despite often limited health gains [7, 8]. This causes particular concern in countries with fixed budgets, with the resultant opportunity cost implications for patients with cancer and other diseases $[9,10]$ leading to prescribing restrictions and other measures to limit their use and reduce the prices of new cancer medicines [11, 12]. Consequently, in European countries with appreciable pressure on resources such as Kosovo, there is an imperative need to review current utilization and expenditure patterns for cancer medicines, as well as the selection process for new anti-cancer medicines, to make sure available resources are being optimally used. In recent years the prevalence of cancers in Kosovo has been increasing [13]. In 2015, the greatest incidence was for melanomas and other malignant neoplasms of the skin (411 new cases), breast neoplasms (274 new cases), malignant tumors of the digestive system (262 new cases), and malignant tumors of the genital organs (257 new cases). Together, these made up 1204 of the total 1751 new cases of cancer in Kosovo 2015 [14].

In addition, reports following $\mathrm{MoH}$ workshops have suggested that in 2017 there is an increasing trend in the total number of cancers in Kosovo, and that some of these cases are due to better diagnostics and awareness campaigns leading to more patients being diagnosed earlier (A. Jakupi, unpublished data).

The Kosovo University Clinical Center Service (KUCCS) is a key institution in Kosovo's health system as all of the hospitals that offer secondary and tertiary-level care, such as the University Clinical Centre of Kosovo (UCCK), function within its framework. The Oncology Institute operates within the UCCK and KUCCS framework and, along with other institutes, also deals with the overall management of cancer patients in Kosovo, including chemotherapy and radiotherapy. The supply of medicines in UCCK is undertaken through the central pharmacy, which supplies all clinics.

However, little is known generally about medicine consumption in Kosovo including anti-cancer medicines, although drug consumption data for 2011-2013 were published by the KMA in 2014. In addition, the procurement process of the $\mathrm{MoH}$ is now centralized, as recommended by the World Health Organization (WHO) and the World Bank [15]. In contrast, the other processes have been decentralized since 2015 as every hospital, through its own structures, is now responsible for the planning, selection, and ordering of medicines and equipment.

The current selection process to update the oncology medicine list begins with physicians, in this case those in the Institute of Oncology. The list and suggested changes are subsequently reviewed by the head of the clinic, the central pharmacy director, and the general director of the hospital. After this process, the suggested updated list is submitted to the professional working group of the $\mathrm{MoH}$ for the final review and approval by the Minister of Health. Figure 1 illustrates this process.

Once the list is signed by the Minister, the second part of the drug management process proceeds, i.e., the procurement of the medicines from the agreed essential medicines list intended for hospital use. This process is carried out in a centralized way by the MoH for all hospitals in Kosovo, 
Fig. 1 Selection process for updating the Essential Medicines List for new anticancer medicines (based on Quick et al. [16])

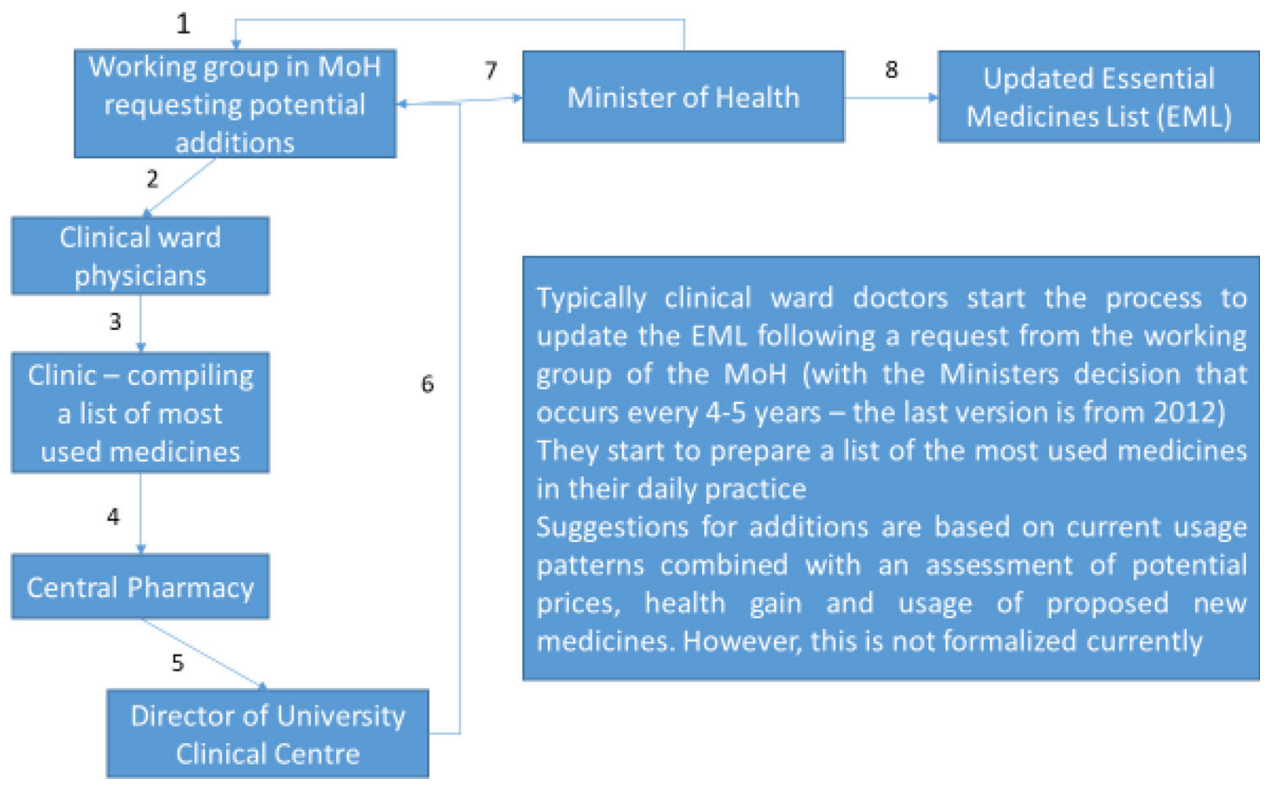

with the system being transparent to help reduce possible corruption [17]. After this, the process is continued with the distribution to the central pharmacies (of each hospital), from where available medicines are supplied to all of the clinics. This process is carried out under the supervision of the chief pharmacists of the hospitals, ready for clinicians to use the oncology medicines in their clinics.

Consequently, the aim of this paper is to critically review the utilization of and expenditure on anti-cancer medicines in Kosovo, including the selection processes for listing medicines in Kosovo. The findings are then used to suggest future strategies in Kosovo to improve the use of cancer medicines within available resources, building on the expertise of the co-authors working with health authorities across Europe, including Kosovo and wider, and their networks.

\section{Methodology}

The drug utilization and expenditure data were obtained from the $\mathrm{MoH}$ and the wholesale drug suppliers, similar to those for other disease areas [18]. Due to the lack of electronic reporting systems currently in Kosovo, unlike in the Nordic countries and Scotland as well as other central and eastern European countries [19-25], these data have to be manually recorded. Kosovo's pharmaceutical sector has two main parts: the private sector where drug dispensing for ambulatory care patients is achieved through the 621 pharmacies in the country [26]; and the public sector, which includes hospitals supplied with medicines from the Essential Medicines List, previously procured through the central procurement of the $\mathrm{MoH}$-these medicines are provided only to hospitalized patients.
The utilization of anti-cancer drugs in Kosovo is based on 58 molecules currently available in the Essential Medicine List (EML) according to their generic name or International Nonproprietary Name (INN) [27] each calendar year. For this initial study, data were collected from wholesalers for the 2011-2013 period [28], as all of the licensed wholesalers in Kosovo are obliged to make an application to the KMA for all medicines they import, which includes their INN name, brand (originator) name, dosage form, strength, serial number, and quantity. The reason for the 3-year period was that this was the first official publication by the KMA on drug consumption in Kosovo, providing a basis for future reporting [29]. The methodology is based on the Anatomical Therapeutic Chemical (ATC) drug classification methodology, which is internationally recognized as the standard for undertaking drug utilization research [30-34]. Datasets recorded including the dose, strength, unit quantity, per unit, and overall expenditure for each anti-cancer medicine. Pricing data came from the $\mathrm{MoH}$ [29]. Expenditure was recorded in euros as this is the official currency in Kosovo.

Other sources of drug consumption data include the hospital selection and planning of the medicines process, with data collected from the working group in the $\mathrm{MoH}$ [Ministers decision 60/13 (16 April 2013) and 74/13 (5 June 2013)]. This group has the duty of categorizing the various medicines, including cancer medicines, into VEN (Vital, Essential, Necessary) categories as per WHO recommendations [35]; one of the authors (AJ) is a consultant to the MoH leading the group for this type of analysis. The data were further analyzed and interpreted for this publication. The data were collected in Microsoft Excel ${ }^{\circledR}$ (Microsoft Corp., Redmond, WA, USA) and subsequently converted into informative figures and tables. 
The analysis of oncology medicines is based on the essential list of cancer medicines approved by the $\mathrm{MoH}$ (which is also public). The list of medicines is broken down by overall expenditure during the study period and then by overall class and year before concentrating on the anticancer medicines with the highest expenditures. Anti-cancer medicines are classified by VEN as per the $\mathrm{MoH}$ working group. This is similar to the VEN analysis and $\mathrm{ABC}$ analysis (typically Class A medicines include $10-20 \%$ of the items under consideration but constitute $75-80 \%$ of total expenditure, Class B constitutes 10-20\% of the items under consideration but $15-20 \%$ of total expenditure, and Class $\mathrm{C}$ constitutes the remaining items but only $5-10 \%$ of total expenditure) methodology of the WHO [16, 35, 36]. The analysis of the 15 anti-cancer medicines with the highest expenditures uses different time periods in view of the appreciable variation that can occur across the years.

In accordance with the WHO ATC classification system, the active substances were divided into different groups in relation to the organ or system on which they act and their therapeutic, pharmacological, and chemical properties $[30,37]$. Medicines are classified into groups at five different levels, including 14 main groups (first level), and further divided into different pharmacological/therapeutic subgroups (second level). The third and fourth levels are the chemical/pharmacological/therapeutic subgroups and the fifth level is the chemical substance. Analysis of medicines according to their ATC classification is used for comparative purposes across countries [38], provides an overview, and shows trends in medicine utilization in relation to the different therapeutic areas.

\section{Results}

In this analysis, according to the ATC Level 3, the L01X subgroup (other neoplastic agents) of cancer medicines has the greatest expenditure and they are also utilized more than other anti-cancer medicine groups, followed by the L03A group (immunostimulants) (Fig. 2).

From Fig. 3, it can be seen that only a few anti-cancer medicines currently have high expenditures in Kosovo, with expenditure on bevacizumab, rituximab, and the interferons increasing but variable expenditure on trastuzumab. These anti-cancer medicines were chosen for illustrative purposes to demonstrate the appreciable variation in expenditure that can occur between the years, as well as the limited expenditure on certain proven anticancer medicines on the list of 58 essential medicines currently available. Analysis of the 15 highest expenditure items (Fig. 4) gives us further details of key anti-cancer medicines to concentrate on for future analysis. Figure 5 depicts the anti-cancer medicines with the lowest expenditures in recent years, again providing baseline data for future policies and guidelines.

Figures 4 and 5 show the total expenditure, and the VEN categorization, for the various anti-cancer medicines being utilised in Kosovo. They show that medicines that have a low value per unit (ampoule), such as $€ 2$ or $€ 3$ per ampoule or similar, did not appear to be ordered by the Oncology Institute, whilst there was a tendency to procure higher-cost medicines. Table 1 shows that the final 15 anti-cancer medicines on the Kosovo EML, when sorted by expenditure within a year, have zero orders, whilst the five prior products at the end of the list amounted to $€ 2572$ in totalless than the expenditure on two ampoules of the first anticancer medicine on the list (Table 1).

Table 1 shows that eight medicines that are categorized as vital, and comprise $13.7 \%$ of the essential list of anticancer medicines, have not been ordered at all by the competent authority. In addition, there are 15 molecules that have not been ordered at all (from all three categories of $\mathrm{V}, \mathrm{E}$, and $\mathrm{N}$ ) that comprise $25.86 \%$ of the total oncology list.

\section{Discussion}

We believe that there are interesting findings from this study that can provide future direction to the authorities in Kosovo. When comparing our findings with Norway, a European country with one of the highest GDPs (gross domestic product) per capita, versus Kosovo, with one of the lowest, differences can be seen. This is especially evident when comparing the L01X subgroup in 2013, which makes up $61.8 \%$ of the ATC code L (ATC L) group in Kosovo, while the same subgroup only constitutes $22 \%$ of the ATC L group in Norway [39]. The L04A group (immunosuppressants) comprised 55\% of the total expenditure in Norway versus Kosovo where this same subgroup constituted only 2\% of the ATC L group in 2013.

The appreciable differences in the relative consumption of anti-cancer medicines between countries may be regarded as being attributable to a lack of available resources in Kosovo or, alternatively, resources being wasted in one country versus another. On the other hand, differences in percentage utilization among specific medicines in an ATC group across similar time periods, such as immunosuppressants, can be considered to be an indication that current treatment patterns need to be further evaluated to optimize care within finite resources. According to Fig. 5 and Table 1, paclitaxel, which is included in two dosage forms (30 and $100 \mathrm{mg}$ ) in the EML, is shown to have zero orders-a medicine which now has quite a low acquisition cost and significantly lower prices than other anti-cancer 


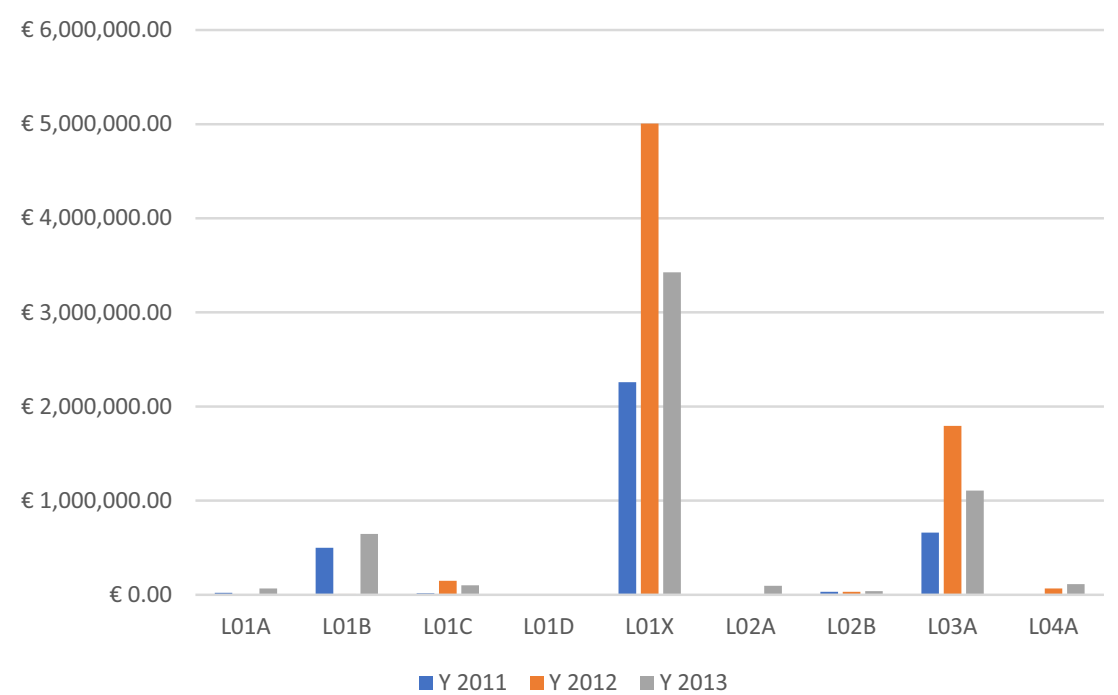

Fig. 2 Expenditure on anti-cancer medicines in Kosovo 2011-2013. $L 01 A$ alkylating medicines, $L 01 B$ antimetabolites, $L 01 C$ plant alkaloids and other natural products, $L 01 D$ cytotoxic antibiotics and other related substances, $L 01 X$ other neoplastic agents including cisplatin, carboplatin and rituximab, $L 02 \mathrm{~A}$ hormones and related substances, $L 02 B$ hormone antagonists and other related substances, LO3A immunostimulants, $L 04 A$ immunosuppressants, $Y$ year (adapted from Drug Consumption in Kosovo [29])
Fig. 3 Breakdown of individual anti-cancer medicines by expenditure 2011 to 2013 (adapted from Drug Consumption in Kosovo [29])

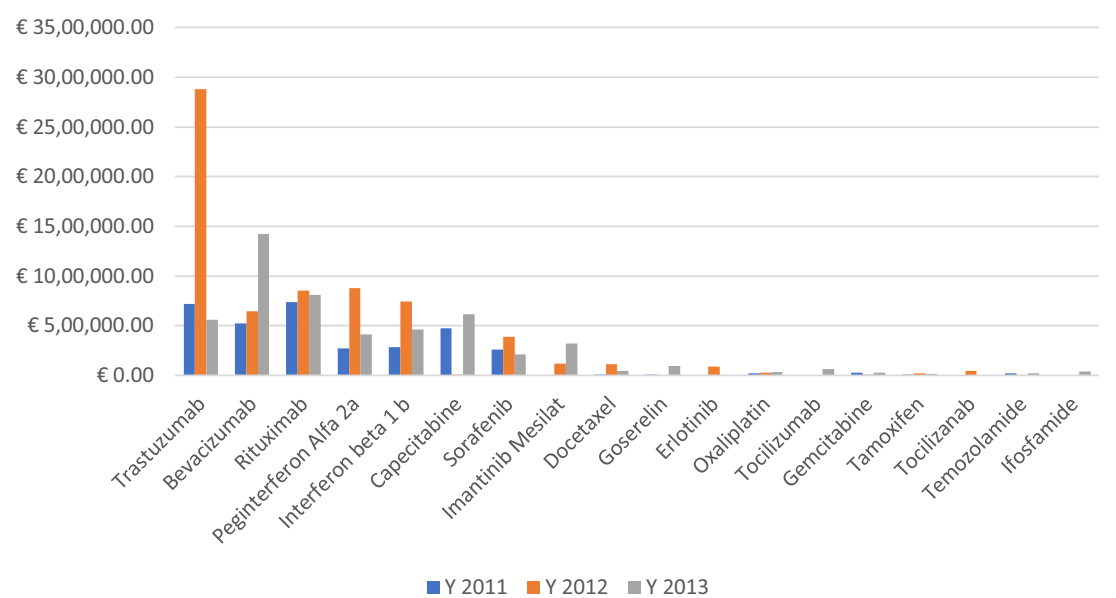

medicines currently being used for similiar indications. In the taxanes group, docataxel and paclitaxel have been key components of chemotherapy regimens since the 1990s, and they are usually prescribed after anthracycline-based chemotherapy [40]. The paper by Webber-Foster et al. [40] does not specify which taxane is preferred since they are considered to be similar in effectiveness, albeit with differences in adverse effects and costs. More lives could potentially be saved with paclitaxel but with higher costs than docataxel [40], although this is not universal. The WHO expert committee, for instance, concludes that both taxanes should be available for breast cancer treatment. This is because, at present, their use, based on available evidence, is different according to specific subgroups of patients and concomitant treatments. In addition, there are no cost-effectiveness data currently available for different settings, or for different outcomes, leading to both taxanes currently being included in the latest WHO essential list of medicines [41, 42]. A representative of the anthracycline group, daunorubicin (ATC L01DB), also has zero orders (Table 1); this is also a cause for concern. Such discrepancues can also be noted for other medicines in Table 1.

The inclusion of cancer medicines in the EML, and their free availability in hospitals, has benefited a great number of patients with cancer, as currently patients have to cover the full cost of medicines in ambulatory care in Kosovo. However, this will only continue if there is good use of existing resources in hospitals to treat patients with cancer through robust processes for pricing, reimbursing, and funding of medicines, along with a robust process for regularly monitoring their use against agreed guidance. 
Fig. 4 Analysis of the 15 anticancer drugs annual orders with the highest monetary expenditure including VEN (vital, essential, necessary) analysis between 2011 and 2013
Fig. 5 Analysis of the 20 anticancer drugs annual orders with the lowest expenditure including VEN (vital, essential, necessary) analysis between 2011 and 2013
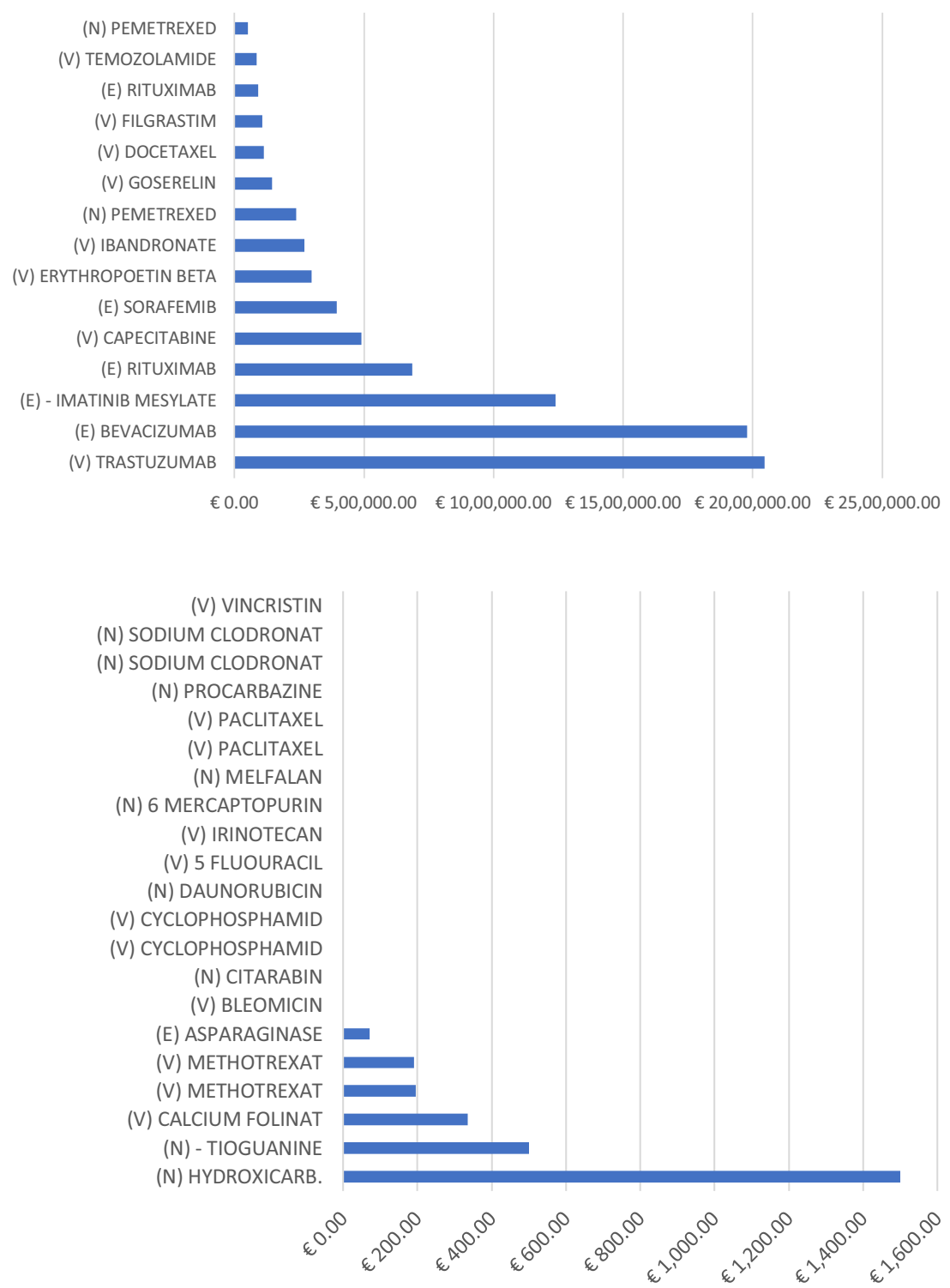

Table 1 and Figs. 3, 4, 5 show that only a few anticancer medicines have very high expenditure in Kosovo, but there use varies across the years, causing concern regarding the most effective use of limited resources. The significant differences in the ordering of cancer medicines such as bevacizumab, trastuzumab, and capecitabine suggest current processes are not coordinated. In addition, there currently appear to be different protocols for treatment of different indications in Kosovo, causing confusion (A. Jakupi, unpublished data). This has implications for any treatment approach in hospitals in Kosovo. In addition, $13.7 \%$ of cancer medicines which were categorized as vital (Table 1) had zero orders, which is a concern as these medicines are regarded as very necessary. Similarly, 15 products from the essential list of anti-cancer medicines (from the three categories of $\mathrm{V}, \mathrm{E}$, or $\mathrm{N}$ ), or $25.86 \%$ of these medicines, had zero orders (Fig. 5, Table 1). With closer scrutiny (Table 1), it can be seen that the prices of these products do not surpass $€ 26$ per ampoule, whilst medicines costing more than $€ 1000$ per ampoule have orders that in total make up the largest expenditures (Figs. 3, 4).

As a result, we believe that competent authorities nationally and in hospitals should review and update their processes to make the selection and planning process relating to anti-cancer medicines a continuous and robust process that adheres to the regulations for essential medicines and pharmacoeconomic analyses. This is currently not the case even with the new procurement process. In addition, there should be regular monitoring of the use of medicines and the expenditure on them in practice against an agreed single guidance, rather than multiple 
Table 1 Expenditure and VEN (vital, essential, necessary) analyses of anti-cancer medicines in Kosovo

\begin{tabular}{|c|c|c|c|c|c|c|c|c|c|}
\hline No. & Generic name & Pharmaceutical form & $\begin{array}{l}\text { Dose and } \\
\text { volume }\end{array}$ & $\mathrm{V}$ & $\mathrm{E}$ & $\mathrm{N}$ & $\begin{array}{l}\text { 12-month } \\
\text { quantity }\end{array}$ & $\begin{array}{l}\text { Price/unit } \\
(€)\end{array}$ & $\begin{array}{l}\text { Expenditure } \\
(€)\end{array}$ \\
\hline 1 & Trastuzumab & Concentration per solution per infusion & $440 \mathrm{mg}$ & $\mathrm{V}$ & & & 1320 & 1550.00 & $2,046,000.0$ \\
\hline 2 & Bevacizumab & Concentration per solution per infusion & $\begin{array}{r}400 \mathrm{mg} / \\
16 \mathrm{~mL}\end{array}$ & & $\mathrm{E}$ & & 6400 & 309.00 & $1,977,600.00$ \\
\hline 3 & Imatinib mesylate & Tablet & $400 \mathrm{mg}$ & & $\mathrm{E}$ & & 12,600 & 98.30 & $1,238,580.00$ \\
\hline 4 & Rituximab & Concentration per solution per infusion & $500 \mathrm{mg}$ & & $\mathrm{E}$ & & 600 & 1145.00 & $687,000.00$ \\
\hline 5 & Capecitabine & Tablet & $500 \mathrm{mg}$ & $\mathrm{V}$ & & & 210,000 & 2.33 & $489,300.00$ \\
\hline 6 & Sorafemib & Tablet & $200 \mathrm{mg}$ & & $\mathrm{E}$ & & 10,800 & 36.50 & $394,200.00$ \\
\hline 7 & Erythropoetin beta & Prefilled syringe & $30,000 \mathrm{IU}$ & $\mathrm{V}$ & & & 1800 & 165.00 & $297,000.00$ \\
\hline 8 & Ibandronate & Concentration per solution per infusion & $6 \mathrm{mg}$ & $\mathrm{V}$ & & & 2160 & 125.00 & $270,000.00$ \\
\hline 9 & Pemetrexed & Powder concentration per solution & $500 \mathrm{mg}$ & & & $\mathrm{N}$ & 240 & 990.00 & $237,600.00$ \\
\hline 10 & Goserelin & Prefilled syringe & $10.8 \mathrm{mg}$ & $\mathrm{V}$ & & & 480 & 302.00 & $144,960.00$ \\
\hline 11 & Docetaxel & $\begin{array}{l}\text { Concentration and dilution per solution } \\
\text { per infusion }\end{array}$ & $\begin{array}{l}40 \mathrm{mg} / \mathrm{mL} \\
2 \mathrm{~mL}\end{array}$ & $\mathrm{~V}$ & & & 4800 & 23.73 & $113,904.00$ \\
\hline 12 & Filgrastim & Solution per infusion & $48 \mathrm{MIU}$ & V & & & 3000 & 36.00 & $108,000.00$ \\
\hline 13 & Rituximab & Concentration per solution per infusion & $100 \mathrm{mg}$ & & $\mathrm{E}$ & & 400 & 230.00 & $92,000.00$ \\
\hline 14 & Temozolamide & Capsules & $250 \mathrm{mg}$ & V & & & 1680 & 50.86 & $85,444.80$ \\
\hline 15 & Pemetrexed & Powder concentration per solution & $100 \mathrm{mg}$ & & & $\mathrm{N}$ & 240 & 220.00 & $52,800.00$ \\
\hline 16 & Cisplatin & Powder concentration per injection & $50 \mathrm{mg}$ & $\mathrm{V}$ & & & 3960 & 13.00 & $51,480.00$ \\
\hline 17 & Anastrazole & Tablet & $1 \mathrm{mg}$ & $\mathrm{V}$ & & & 60,000 & 0.82 & $49,200.00$ \\
\hline 18 & Ibandronate & Tablet & $50 \mathrm{mg}$ & $\mathrm{V}$ & & & 7392 & 6.00 & $44,352.00$ \\
\hline 19 & Gemcitabine & Powder concentration per solution & $1000 \mathrm{mg}$ & $\mathrm{V}$ & & & 1800 & 19.90 & $35,820.00$ \\
\hline 20 & Carboplatin & Solution per infusion & $\begin{array}{l}10 \mathrm{mg} / \mathrm{mL} \\
45 \mathrm{~mL}\end{array}$ & $\mathrm{~V}$ & & & 1400 & 24.50 & $34,300.00$ \\
\hline 21 & Cyproterone acetate & Tablet & $50 \mathrm{mg}$ & V & & & 39,600 & 0.77 & $30,492.00$ \\
\hline 22 & Doxorubicin & Powder concentration per injection & $50 \mathrm{mg}$ & V & & & 3480 & 8.20 & $28,536.00$ \\
\hline 23 & Oxaliplatin & Concentration per solution per infusion & $100 \mathrm{mg}$ & V & & & 1800 & 15.00 & $27,000.00$ \\
\hline 24 & Gemcitabine & Powder concentration per solution & $200 \mathrm{mg}$ & V & & & 3600 & 6.00 & $21,600.00$ \\
\hline 25 & Interferon- $\alpha-2 \mathrm{a}$ & Prefilled syringe & $3 \mathrm{MIU} / 5 \mathrm{~mL}$ & & & $\mathrm{~N}$ & 1560 & 13.50 & $21,060.00$ \\
\hline 26 & Dacarbazine & $\begin{array}{l}\text { Powder concentration per solution per } \\
\text { infusion }\end{array}$ & $200 \mathrm{mg}$ & V & & & 900 & 22.66 & $20,394.00$ \\
\hline 27 & Fludarabine & Tablet & $10 \mathrm{mg}$ & & $\mathrm{E}$ & & 600 & 29.00 & $17,400.00$ \\
\hline 28 & $\begin{array}{l}\text { Bacillus Calmette- } \\
\text { Guerin }\end{array}$ & Powder concentration per solution & $81-100 \mathrm{mg}$ & & & $\mathrm{N}$ & 200 & 70.00 & $14,000.00$ \\
\hline 29 & Doxorubicin & Powder concentration per injection & $10 \mathrm{mg}$ & $\mathrm{V}$ & & & 2880 & 3.00 & 8640.00 \\
\hline 30 & Ifosfamide & Powder concentration per injection & $1 \mathrm{~g}$ & $\mathrm{~V}$ & & & 420 & 18.90 & 7938.00 \\
\hline 31 & Etoposide & Solution per infusion & $100 \mathrm{mg}$ & $\mathrm{V}$ & & & 1800 & 3.73 & 6714.00 \\
\hline 32 & Chlorambucil & Tablet & $2 \mathrm{mg}$ & & & $\mathrm{N}$ & 600 & 10.00 & 6000.00 \\
\hline 33 & 5-Fluorouracil & Solution per injection & $\begin{array}{l}50 \mathrm{mg} / \mathrm{mL} \\
10 \mathrm{~mL}\end{array}$ & $\mathrm{~V}$ & & & 2000 & 2.56 & 5120.00 \\
\hline 34 & Tamoxifen & Tablet & $20 \mathrm{mg}$ & V & & & 48,000 & 0.10 & 4656.00 \\
\hline 35 & Fludarabine & Powder concentration per injection & $50 \mathrm{mg}$ & & $\mathrm{E}$ & & 120 & 30.00 & 3600.00 \\
\hline 36 & Mesna & Tablet & $400 \mathrm{mg}$ & $\mathrm{V}$ & & & 840 & 3.90 & 3275.16 \\
\hline 37 & Vinblastine & Solution per injection & $\begin{array}{l}1 \mathrm{mg} / \mathrm{mL} \text {, } \\
10 \mathrm{~mL}\end{array}$ & V & & & 340 & 5.88 & 1999.20 \\
\hline 38 & Hydroxycarbamide & Capsules & $500 \mathrm{mg}$ & & & $\mathrm{N}$ & 10,000 & 0.15 & 1500.00 \\
\hline 39 & Tioguanine & Tablet & $40 \mathrm{mg}$ & & & $\mathrm{N}$ & 200 & 2.50 & 500.00 \\
\hline 40 & Calcium folinate & Solution per injection & $\begin{array}{l}10 \mathrm{mg} / \mathrm{mL} \\
5 \mathrm{~mL}\end{array}$ & V & & & 80 & 4.20 & 336.00 \\
\hline 41 & Methotrexate & Tablet & $2.5 \mathrm{mg}$ & V & & & 1500 & 0.13 & 195.00 \\
\hline
\end{tabular}


Table 1 continued

\begin{tabular}{|c|c|c|c|c|c|c|c|c|}
\hline No. & Generic name & Pharmaceutical form & $\begin{array}{l}\text { Dose and } \\
\text { volume }\end{array}$ & $\mathrm{V} \quad \mathrm{E}$ & $\mathrm{N}$ & $\begin{array}{l}\text { 12-month } \\
\text { quantity }\end{array}$ & $\begin{array}{l}\text { Price/unit } \\
(€)\end{array}$ & $\begin{array}{l}\text { Expenditure } \\
(€)\end{array}$ \\
\hline 42 & Methotrexate & Solution per injection & $\begin{array}{l}50 \mathrm{mg} / \mathrm{mL}, \\
1 \mathrm{~mL}\end{array}$ & V & & 60 & 3.19 & 191.40 \\
\hline 43 & Asparaginase & Solution per injection & $\begin{array}{c}10 \mathrm{MIU}, \\
10 \mathrm{~mL}\end{array}$ & & & 36 & 2.00 & 72.00 \\
\hline 44 & Bleomycin & Powder concentration per infusion & $15 \mathrm{IU}$ & $\mathrm{V}$ & & 0 & 26.60 & \\
\hline 45 & Citarabine & Solution per injection & $\begin{array}{l}100 \mathrm{mg} / \mathrm{mL} \text {, } \\
1 \mathrm{~mL}\end{array}$ & & $\mathrm{~N}$ & 0 & 3.50 & \\
\hline 46 & Cyclophosphamide & Powder concentration per solution & $200 \mathrm{mg}$ & V & & 0 & 2.59 & \\
\hline 47 & Cyclophosphamide & Powder concentration per solution & $1000 \mathrm{mg}$ & $\mathrm{V}$ & & 0 & 5.69 & \\
\hline 48 & Daunorubicin & Powder concentration per injection & $20 \mathrm{mg}$ & & $\mathrm{N}$ & 0 & 12.23 & \\
\hline 49 & 5-Fluorouracil & Solution per injection & $\begin{array}{l}50 \mathrm{mg} / \mathrm{mL}, \\
5 \mathrm{~mL}\end{array}$ & V & & 0 & 1.68 & \\
\hline 50 & Irinotecan & Concentration per solution per infusion & $\begin{array}{l}20 \mathrm{mg} / \mathrm{mL}, \\
5 \mathrm{~mL}\end{array}$ & $\mathrm{~V}$ & & 0 & 18.00 & \\
\hline 51 & 6-Mercaptopurine & Tablet & $50 \mathrm{mg}$ & & $\mathrm{N}$ & 0 & 1.50 & \\
\hline 52 & Melphalan & Tablet & $2 \mathrm{mg}$ & & $\mathrm{N}$ & 600 & & \\
\hline 53 & Paclitaxel & Concentration per solution per infusion & $100 \mathrm{mg}$ & $\mathrm{V}$ & & 0 & 16.00 & \\
\hline 54 & Paclitaxel & Concentration per solution per infusion & $30 \mathrm{mg}$ & V & & 0 & 6.30 & \\
\hline 55 & Procarbazine & Tablet & $50 \mathrm{mg}$ & & $\mathrm{N}$ & 0 & & \\
\hline 56 & Sodium clodronate & Capsules & $800 \mathrm{mg}$ & & $\mathrm{N}$ & 0 & 3.94 & \\
\hline 57 & Sodium clodronate & Concentration per solution per infusion & $\begin{array}{l}60 \mathrm{mg} / \mathrm{mL}, \\
5 \mathrm{~mL}\end{array}$ & & $\mathrm{~N}$ & 0 & 15.86 & \\
\hline 58 & Vincristine & Solution per injection & $\begin{array}{c}1 \mathrm{mg} / \mathrm{mL}, \\
1 \mathrm{~mL}\end{array}$ & V & & 0 & 8.50 & \\
\hline
\end{tabular}

Caps capsule, Conc concentration, Dil dilutant, $E$ essential, Inf infusion, Inj injection, $I U$ international units, $m g$ milligram, $m l$ millilitre, $M I U$ million internationalunits, $N$ necessary, $P l v$ pulvis - powder, Sol solution, $T b l$ tablet, $V E N$ Vital - Essential - Necessary, $V$ vital

guidances, to improve future care efficiently, as seen in other countries such as Sweden [2, 11, 43]. There are serious concerns relating to different guidances from different national and international groups giving conflicting advice [44] as this is not in the best interest of any key stakeholder group.

Pharmacoeconomic analysis in accordance with Pallis et al. [45] should help improve decision-making in Kosovo in such a way that would optimize the use of already limited resources dedicated to the treatment of cancer patients. This is essential with limited resources as per the concept of opportunity cost [9].

We accept that there are a number of limitations to this study. This includes the fact that there is currently no information on the extent to which people are travelling from neighboring countries to Kosovo for treatment. There is also no doubt that available databases contain incomplete information as there is currently considerable reliance on manually recorded information. However, we believe our findings are robust, providing future direction to all key stakeholder groups in Kosovo in this important disease area.

\section{Recommendations}

In view of our findings, we believe that the $\mathrm{MoH}$ in Kosovo should take a lead role in updating current regulations regarding that the process of selection of new and existing medicines and including/excluding medicines from the essential list, including active disinvestment, where appropriate. In addition, the MoH should clearly define the use of and need for pharmacoeconomic analyses to aid reimbursement and funding decisions, encourage the use of drug utilization studies to monitor the use of anti-cancer medicines in routine care, as well as update and consolidate treatment protocols into a single source, replacing the current confusion. Regularly monitoring the utilization and expenditure on anti-cancer medicines will highlight if any agreed essential medicines are currently not being used. Key clinicians should be part of any guideline development and monitoring processes in order to enhance their adherence to jointly agreed medicines and their use, which has worked well in other countries [46]. The MoH should also separately look at its procurement process, including prices for similar medicines in neighboring countries, to again 
optimize the use of available resources. Pharmacoeconomics, including value-based pricing, should be part of this.

Furthermore, the MoH could also explore the potential of delegating some of its responsibility to a working group, which could include Drug and Therapy Committees, to regularly monitor the prescription and consumption of medicines in high-priority areas such as cancer. In this way, the drug management cycle would be improved as all parts of the chain would be more precisely monitored and performed. The inclusion of electronic systems in the future will further help with such processes. This will form part of future research projects in Kosovo.

\section{Conclusion}

In this article we have shown discrepancies regarding current procedures relating to the utilization of and expenditure on anti-cancer medicines in Kosovo, including no or limited utilization of anti-cancer medicines currently deemed essential. Our findings have been used to make suggestions for improved processes in order to better manage patients with cancer in Kosovo given the limited resources available. These findings will be followed up in the future to help improve the care of these patients despite the likely continued limited resources in Kosovo.

Author contributions AJ, IB and BBG developed the concept of the paper, $\mathrm{AJ}$ undertook the analysis; $\mathrm{BBG}, \mathrm{AM}, \mathrm{AL}$ and $\mathrm{IB}$ helped with the interpretation of the findings. AJ, BBG, AM and AL help draft the initial manuscript. All authors were involved with the submission and the revised manuscript.

Data Availability Some of the analyzed materials have been taken from a previous reports of the Ministry of Health of Kosovo, but reanalyzed including utilization patterns and other related indicators for this particular paper. Previous publications include: Jakupi A et al (2013), Analysis of the Essential List for 2013 including VEN and ABC indicators. Ministry of Health. Prishtina, Kosovo and Jakupi A. (2014) Drug Consumption in Kosovo 2011-2013, Kosovo Medicines Agency. Prishtinë Kosovë. Other related materials were collected in Ministry of Health and University Clinical Centre of Kosovo. However, these are not available for open access.

\section{Compliance with Ethical Standards}

Funding No funding was received for this study.

Conflict of interest There was no financial support for this study. The authors (Arianit Jakupi, Brian Godman, Antony Martin, Alan Haycox, and Indrit Baholli) declare they have no conflicts of interest.

Open Access This article is distributed under the terms of the Creative Commons Attribution-NonCommercial 4.0 International License (http://creativecommons.org/licenses/by-nc/4.0/), which permits any noncommercial use, distribution, and reproduction in any medium, provided you give appropriate credit to the original author(s) and the source, provide a link to the Creative Commons license, and indicate if changes were made.

\section{References}

1. Godman B, Wettermark B, van Woerkom M, Fraeyman J, Alvarez-Madrazo S, Berg C, et al. Multiple policies to enhance prescribing efficiency for established medicines in Europe with a particular focus on demand-side measures: findings and future implications. Front Pharmacol. 2014;5:106.

2. Wettermark B, Godman B, Neovius M, Hedberg N, Mellgren TO, Kahan T. Initial effects of a reimbursement restriction to improve the cost-effectiveness of antihypertensive treatment. Health Policy. 2010;94(3):221-9.

3. Wettermark B, Zoega H, Furu K, Korhonen M, Hallas J, Norgaard $\mathrm{M}$, et al. The Nordic prescription databases as a resource for pharmacoepidemiological research-a literature review. Pharmacoepidemiol Drug Saf. 2013;22(7):691-9.

4. Sakshaug S, Furu K, Karlstad O, Ronning M, Skurtveit S. Switching statins in Norway after new reimbursement policy: a nationwide prescription study. $\mathrm{Br} \mathrm{J}$ Clin Pharmacol. 2007;64(4):476-81.

5. Haycox A. Why cancer? Pharmacoeconomics. 2016;34(7):625-7.

6. New 50 million pound cancer fund already intellectually bankrupt. Lancet. 2010;376(9739):389.

7. Kelly RJ, Smith TJ. Delivering maximum clinical benefit at an affordable price: engaging stakeholders in cancer care. Lancet Oncol. 2014;15(3):e112-8.

8. WHO. Access to new medicines in Europe: technical review of policy initiatives and opportunities for collaboration and research. http://www.euro.who.int/_data/assets/pdf_file/0008/306179/ Access-new-medicines-TR-PIO-collaboration-research.pdf?ua=1. Accessed 16 May 2017.

9. Barrett A, Roques T, Small M, Smith RD. How much will Herceptin really cost? BMJ. 2006;333(7578):1118-20.

10. Ghinea H, Kerridge I, Lipworth W. If we don't talk about value, cancer drugs will become terminal for health systems. http:// theconversation.com/if-we-dont-talk-about-value-cancer-drugswill-become-terminal-for-health-systems-44072. Accessed 10 May 2017.

11. Matusewicz W, Godman B, Pedersen HB, Furst J, Gulbinovic J, Mack A, et al. Improving the managed introduction of new medicines: sharing experiences to aid authorities across Europe. Expert Rev Pharmacoecon Outcomes Res. 2015;15(5):755-8.

12. Ferrario A, Kanavos P. Managed entry agreements for pharmaceuticals: the European experience. Brussels: EMiNet; 2013. http://eprints.lse.ac.uk/50513/. Accessed 29 Apr 2017.

13. Ministry of Health of Kosovo. Health sectorial strategy 2017-2021. 2017. http://www.kryeministri-ks.net/repository/ docs/Strategiia-sektoriale-e-shendetesise-final-nentor-2016-ALB. pdf. Accessed 28 Apr 2017.

14. Statistical Agency of Kosovo. Health statistics in 2015. 2016. http://ask.rks-gov.net/sq/agjencia-e-statistikave-te-kosoves/sociale/ shendetesia-dhe-mireqenia-sociale. Accessed 26 Apr 2017.

15. Lopert R. Republic of Kosovo-review of oncology formulary. World Bank Report. 2014. Washington, DC: World Bank; 2015.

16. Quick JD, Hogerzeil H Hogerzeil, Rankin, JR, Dukes MNG, Laing $\mathrm{R}$, et al. (eds). Economics, pharmaceuticals in managing drug supply: the selection, procurement, distribution, and use of pharmaceuticals. Management sciences for health in collaboration with the World Health Organization. West Hartford: Kumarian Press; 1997. http://apps.who.int/iris/handle/10665/ 41908. Accessed 4 May 2017. 
17. Transparentitis virus: public procurement monitoring at the Ministry of Health. 2016. http://www.kdi-kosova.org/publikime/ 74-2016-03-31-virusi-transparentitis_eng_final_isbn.pdf. Accessed 4 May 2017.

18. WHO. Antimicrobial Medicines Consumption (AMC) Network. AMC data 2011-2014. 2017. http://www.euro.who.int/en/ publications/abstracts/antimicrobial-medicines-consumptionamc-network.-amc-data-20112014-2017. Accessed 6 May 2017.

19. Alvarez-Madrazo S, McTaggart S, Nangle C, Nicholson E, Bennie M. Data resource profile: the Scottish National Prescribing Information System (PIS). Int J Epidemiol. 2016;45(3):714.

20. Wallerstedt SM, Wettermark B, Hoffmann M. The first decade with the Swedish Prescribed Drug Register-a systematic review of the output in the scientific literature. Basic Clin Pharmacol Toxicol. 2016;119(5):464-9.

21. Wettermark B, Zoega H, Furu K, Korhonen M, Hallas J, Nørgaard M. The Nordic prescription databases as a resource for pharmacoepidemiological research - a literature review. Pharmacoepidemiol Drug Saf. 2013;22:691.

22. Godman B, Shrank W, Andersen M, Berg C, Bishop I, Burkhardt $\mathrm{T}$, et al. Policies to enhance prescribing efficiency in europe: findings and future implications. Front Pharmacol. 2010;1:141.

23. Markovic-Pekovic V, Skrbic R, Godman B, Gustafsson LL. Ongoing initiatives in the Republic of Srpska to enhance prescribing efficiency: influence and future directions. Expert Rev Pharmacoecon Outcomes Res. 2012;12(5):661-71.

24. Kalaba M, Godman B, Vuksanovic A, Bennie M, Malmstrom RE. Possible ways to enhance renin-angiotensin prescribing efficiency: Republic of Serbia as a case history? J Comp Eff Res. 2012;1(6):539-49.

25. Voncina L, Strizrep T, Godman B, Bennie M, Bishop I, Campbell $S$, et al. Influence of demand-side measures to enhance reninangiotensin prescribing efficiency in Europe: implications for the future. Expert Rev Pharmacoecon Outcomes Res. 2011;11(4):469-79.

26. Kosovo Medicines Agency. Pharmacies in Kosovo 2017. https:// cloud.akppm.com/public.php?service=files\&t=e13af25d11ae958 885f3c201a595b6af. Accessed 20 Apr 2017.

27. Krasniqi SH. Drug register 4. Prishtinë Kosovë: Kosovo Medicines Agency; 2015.

28. Ministry of Health of Kosovo. Analysis of the essential list for 2013 including VEN and ABC indicators. Kosovo: Prishtina; 2015.

29. Jakupi A. Drug consumption in Kosovo 2011-2013. Prishtinë Kosovë: Kosovo Medicines Agency. http://akppm.com/. Accessed 20 Apr 2017.

30. WHO Collaborating Centre for Drug Statistics Methodology. ATC/DDD Index. https://www.whocc.no/atc_ddd_index/?. Accessed 10 Apr 2017.

31. Bachhav SS, Kshirsagar NA. Systematic review of drug utilization studies and the use of the drug classification system in the WHO-SEARO Region. Indian J Med Res. 2015;142(2):120-9.

32. Chlabicz M, Chlabicz S, Marcinowicz L, Rogowska-Szadkowska D, Pytel-Krolczuk B, Leszczynska K. Outpatient use of systemic antibiotics in Poland: 2004-2008. Przegl Epidemiol. 2014;68(3):435-41.
33. Versporten A, Bolokhovets G, Ghazaryan L, Abilova V, Pyshnik G, Spasojevic T, et al. Antibiotic use in eastern Europe: a crossnational database study in coordination with the WHO Regional Office for Europe. Lancet Infect Dis. 2014;14(5):381-7.

34. Dumartin C, L'Heriteau F, Pefau M, Bertrand X, Jarno P, Boussat $\mathrm{S}$, et al. Antibiotic use in 530 French hospitals: results from a surveillance network at hospital and ward levels in 2007. J Antimicrob Chemother. 2010;65(9):2028-36.

35. WHO. Analyzing and controlling pharmaceutical expenditures. http://apps.who.int/medicinedocs/documents/s19617en/s19617en. pdf. Accessed 4 May 2017.

36. Holloway K, Green T on behalf of the WHO in collaboration with Management Sciences for Health. Drug and therapeutics committees: a practical guide. http://apps.who.int/medicinedocs/pdf/ s4882e/s4882e.pdf. Accessed 4 May 2017.

37. WHO Collaborating Centre for Drug Statistics Methodology. Guidelines for ATC classification and DDD assignment. 2017. https://www.whocc.no/filearchive/publications/guidelines.pdf. Accessed 4 Jan 2018.

38. WHO. Introduction to drug utilization research. http://apps.who. int/medicinedocs/pdf/s4876e/s4876e.pdf. Accessed 10 Apr 2017.

39. Sakshaug S, Strøm H, Berg C, Blix HS, Litleskare I, Granum T. Legemiddelforbruket i Norge 2012-2016 [Drug consumption in Norway 2012-2016]. Oslo: Folkehelseinstituttet/Norwegian Institute of Public Health; 2016.

40. Webber-Foster R, Kvizhinadze G, Rivalland G, Blakely T. Costeffectiveness analysis of docetaxel versus weekly paclitaxel in adjuvant treatment of regional breast cancer in New Zealand. Pharmacoeconomics. 2014;32(7):707-24.

41. NHS CeVEAS. Review of the available evidence on taxanes (paclitaxel and docetaxel) for breast cancer for the inclusion in the WHO Model List of Essential Medicines. http://www.who. int/selection_medicines/committees/expert/18/applications/8_sub mission_taxanes.pdf. Accessed 10 May 2017.

42. WHO. WHO Model List of Essential Medicines-March 2017; Amended August 2017. http://www.who.int/medicines/ publications/essentialmedicines/20th_EML2017_FINAL_amend edAug2017.pdf?ua=1. Accessed 1 Sept 2017.

43. Godman B, Oortwijn W, de Waure C, Mosca I, Puggina A, Specchia ML et al. Links between Pharmaceutical R\&D models and access to affordable medicines. A study for the ENVI Committee. http://www.europarl.europa.eu/RegData/etudes/ STUD/2016/587321/IPOL_STU(2016)587321_EN.pdf. Accessed 10 May 2017.

44. Kibuule D, Mubita M, Naikaku E, Kalemeera F, Godman BB, Sagwa E. An analysis of policies for cotrimoxazole, amoxicillin and azithromycin use in Namibia's public sector: findings and therapeutic implications. Int J Clin Pract. 2017;71(2). https://doi. org/10.1111/ijcp.12918.

45. Pallis A, Tsiantou V, Simou E, Maniadakis N. Pharmacoeconomic considerations in the treatment of breast cancer. ClinicoEcon Outcomes Res. 2010;2:47-61.

46. Bjorkhem-Bergman L, Andersen-Karlsson E, Laing R, Diogene $\mathrm{E}$, Melien $\mathrm{O}$, Jirlow $\mathrm{M}$, et al. Interface management of pharmacotherapy. Joint hospital and primary care drug recommendations. Eur J clin pharmacol. 2013;69:73-8. 